\title{
Microsurgical resection of intramedullary spinal cord hemangioblastoma
}

\author{
Paul C. McCormick, M.D., MPH \\ Columbia University College of Physicians and Surgeons, New York, New York
}

\begin{abstract}
Spinal cord hemangioblastomas account for about $10 \%$ of spinal cord tumors. They usually arise from the dorsolateral pia mater and are characterized by their significant vascularity. The principles and techniques of safe resection are different than those employed for the more commonly occurring intramedullary glial tumors (e.g. ependymoma, astrocytoma) and consist of circumferential detachment of the tumor margin from the surrounding normal pia. This video demonstrates the microsurgical techniques of resection of a thoracic spinal cord hemangioblastoma.

The video can be found here: http://youtu.be/yT5KLi4VyAo.

(http://thejns.org/doi/abs/10.3171/2014.V3.FOCUS14306)
\end{abstract}

KEY Words • hemangioblastoma • spinal cord • tumor • video

Manuscript submitted June 13, 2014.

Accepted July 18, 2014.

Please include this information when citing this paper: DOI: 10.3171/2014.V3.FOCUS14306.

Address correspondence to: Paul C. McCormick, M.D., MPH, 8th

Street, New York, New York 10032. email: pcm6@ columbia.edu. 